\author{
비닐아세테이트 코텔로머의 제조 및 계면활성(I) \\ 이언필 ${ }^{1)} \cdot$ 강세미 $^{1)} \cdot$ 황대연 $^{1)} \cdot$ 정영진 $^{1)} \cdot$ 최해욱 $^{1)} \cdot$ 최영호 $^{2)} \cdot$ 이재호 $^{1)}$ \\ 1)부산대학교 바이오소재과학과 \\ 2)일신텍스타일
}

\title{
Preparation and Surface-Active Properties of Vinyl Acetate Cotelomers (I)
}

\author{
Eon Pil Lee ${ }^{1)}$, Se Mi Kang', Dae Youn Hwang'), Young Jin Jung'), \\ Hae Wook Choi ${ }^{1)}$, Young Ho Choi ${ }^{2)}$, and Jae Ho Lee ${ }^{1) \dagger}$ \\ ${ }^{1)}$ Dept. of Biomaterial Science, Pusan National University; Miryang, Korea \\ ${ }^{2)}$ Ilshintextile; Busan, Korea
}

\begin{abstract}
R}_{8} \mathrm{~S}-\mathrm{nVAc}\right)$ were synthesized and hydrolyzed with sodium hydroxide subsequently, 1.2-epoxyhexane was then introduced to the telomers. In addition, we prepared cotelomers of multi-alkylated nonionic surfactants with a molecular structure of xRnMA-yVA (x; hydrophobic group, y; hydrophilic group, MA; methacrylic ester, VA; vinyl alcohol, R; and alkyl group) and cross-linked with sodium tetraborate decahydrate. Their active surface properties were investigated by several techniques such as surface tension, foaming property, and emulsification power measurements. The surface tension of $\mathrm{R}_{8} \mathrm{~S}-8.8 \mathrm{VA}$ decreased without the introduction of 1.2-Epoxy hexane, and the degree of emulsification and foaming abilities of $\mathrm{R}_{8} \mathrm{~S}-8.8 \mathrm{VA}$ increased without the introduction of 1.2-Epoxy hexane. However, the differences were insignificant. The epoxy groups were attached to a $\mathrm{R}_{8} \mathrm{~S}-8.8 \mathrm{VA}$ cotelomer with a limited variation of the active surface properties. The surface tension of $1.1 \mathrm{R}_{6} \mathrm{MA}-8.8 \mathrm{VA}$ decreased after cross-linking subsequently, the degree of emulsification and foaming abilities of $1.1 \mathrm{R}_{6} \mathrm{MA}-8.8 \mathrm{VA}$ increased after cross-linking. However, there was no clear difference between them. The $\mathrm{B}-\mathrm{O}$ bonds were attached to a $1.1 \mathrm{R}_{6} \mathrm{MA}-8.8 \mathrm{VA}$ cotelomer with a limited variation of the active surface properties.
\end{abstract}

Key words: vinylacetate telomer(비닐아세테이트 텔로머), nonionic surfactants(비이온계면활성제), surface active properties(계면활성), foaming abilities(기포력), emulsification power(유화능)

1. 서

\section{론}

Telomer의 특징은 polymer와 달리, $\mathrm{n}$ 이 1 15 정도의 저중합 물이고, 그 화학구조, 특히 말단기의 구조가 명확한 것이다. 이 와 같은 telomer형 계면활성제에 대하여 최근의 연구는 극히 수가 적다. 그 이유로서 여러 가지가 고려되는데, 이들의 연구 는 대부분 수용성의 일반 계면활성제로서의 응용을 목적으로 하였기 때문에, 수용성 고분자와 저분자 계면활성제의 중간적 성능을 얻는데 그치고, 특징 있는 성능이 기대되지 않았기 때 문으로 여겨진다(Yamada \& Koide, 1981). 지금까지 telomer 에 대한 연구는 용매인 telogen과 불포화화합물인 taxogen의 종류만 바꾸어 계면활성 성질에 대한 연구를 진행한 것이 대부 분이다(Yoshimura et al., 2000, 2001a, 2001b, 2002a, 2002b, 2002c). 여기서 telogen은 계면활성제의 소수기, taxogen은 친수 기로서 주로 기능한다.

†Corresponding author; Jae-Ho Lee

Tel. +82-55-350-5386, Fax. +82-55-350-5389

E-mail: james007din@pnu.ac.kr
최근 micelle계를 이용한 여러 가지의 반응이, 특히 효소유사 기능을 가지는 효소 model로서, 또 천연 및 합성고분자의 주쇄 나 측쇄에 높은 반응성의 치환기를 넣은 기능성고분자가 주목 되어 왔다. 따라서 hydroxyl기와 carboxyl기 등을 비롯한 다수 의 관능기들을 도입하여 그들의 특성에 대한 연구가 행해졌다 (Yamada \& Koide, 1981).

Telomer는 telogen과 taxogen의 종류, telogen과 taxogen의 중합 비, 치환기의 도입 등에 따라 성질이 다르게 된다. 이렇 게 제조된 telomer는 일반적으로 유용한 접착제, 가소제, 섬유, 향료, 플라스틱 및 이들의 중간체로 이용되고 있다(Shim \& Hong, 1962).

선행연구(Lee et al., 2010)에서 친수기를 vinyl alcohol로 하 는 비이온계 다쇄형 계면활성제인 Methacrylic ester-vinyl alcohol cotelomer(xR $\left.\mathrm{x}_{\mathrm{n}} \mathrm{MA}-\mathrm{yVA}\right)$ 를 합성하여 중합도에 따른 염 색조제로서의 효과를 조사한 결과 중합도가 10 , 친수기와 소수 기의 비가 0.2 일 때 가장 좋은 염료분산능 및 염색성을 가지는 것을 확인하였다.

1.2-Epoxyhexane은 Vinyl alcohol의 수산기와 결합하여 에폭 
시 기를 도입하게 하여 각종 수지와의 부착성을 향상시키고, 아 민기나 무수카르본산과 반응하기 쉽게 되는 등 여러 가지 장점 을 부여한다(Moon \& Takaku, 2006). Sodium tetraborate decahydrate는 소량의 양으로 PVA 수용액의 점도를 증가시키 고, PVA의 수산기와 borate 음이온 사이에 B-O결합을 하여 $\mathrm{PVA}$ 체인 간에 일시적으로 가교시키는 역할을 하므로 PVA 제 조 시 증점제와 가교제로서 사용된다(Hyun et al, 2002). 그러 나 이러한 에폭시 기나 B-O 결합 등은 친수기로 친수기가 증 가하면 critical micelle concentration $(\mathrm{cmc})$ 과 표면장력은 증가 하게 되고 거품의 안정성은 떨어져 세정효과를 저하시킬 뿐만 아니라, 염색 시 염료분산능 및 염색성을 떨어뜨리게 된다. 특 히 비이온계 계면활성제의 다양한 응용분야 중에서 가장 중요 한 분야가 전체 생산량의 $50 \%$ 이상이 소요되고 있는 세제 산 업이라고 할 수 있으며, 특히 많은 에너지의 절약이 가능한 낮 은 온도에서의 washing(low temperature detergency)이 중요하 게 대두됨에 따라 비이온 계면활성제의 중요성이 더해 가고 있 다(Lim et al., 2011)

따라서 본 연구에서는 비이온계 다쇄형 계면활성제 Octanethiol vinylacetate cotelomer $\left(\mathrm{R}_{8} \mathrm{~S}-\mathrm{nVA}\right)$ 의 vinyl alcohol 부분에는 1.2-Epoxyhexane을, $\mathrm{xR}_{\mathrm{n}} \mathrm{MA}-\mathrm{yVA}$ 의 vinyl alcohol 부분에는 Sodium tetraborate decahydrate를 도입하여 계면화학 특성을 검토하는 것을 목적으로 하였고, 이후 연구에서는 이들 의 계면활성제를 사용하여 염색성 및 세정효과 등을 검토하고 자 한다.

\section{2. 실 험}

\section{1. 시약}

Telomerization에 사용하는 Vinyl acetate monomer(Kishida Chemical Co., Ltd)류는 구입하여 정제하여 사용하였다. 2Aminoethanthiol hydrochloride, Hexylmethacrylate, $\alpha$ $\alpha$ 'Azobisisobutyronitrile(AIBN), 1-octanethiol, 1.2-Epoxy hexane(Tokyo Chemical Ind.), Sodium hydroxide, acetone, hexane(Nacalai tesque Co. Ltd), Ethanol(Japan alcohol), methanol(Kanto Kagaku), Sodium tetraborate decahydrate (Wako Pure Chemical Ind., Ltd), Toluene(Daejung Chemicals \& Metals Co. Ltd)은 EP 등급을 구입하여 그대로 사용하였다.

\section{2. $\mathrm{R}_{8} \mathrm{~S}-\mathrm{nVA}$ 를 사용한 1.2-Epoxy hexane의 도입}

$\mathrm{R}_{8} \mathrm{~S}-\mathrm{nVAc}$ 의 합성: 온도계, 환류냉각관, 질소 도입관, 적하 funnel을 부착한 4구 플라스크에, 에탄올로 용해시킨 1Octanethiol $\left(\mathrm{R}_{8} \mathrm{~S}\right)$ 및 Vinylacetate monomer $(\mathrm{VAc})$ 를 소정량 넣 어, monomer에 대하여 개시제로서 $\mathrm{AIBN}$ 을 $1.0 \mathrm{wt} \%$ 가하여, 질소기류 하 $60^{\circ} \mathrm{C}$ 에서 6 시간 교반하였다. 반응용액은 에탄올을 감압증류 후, 헥산에 부어서 세정하고, 석출한 점상 물질을 메 탄올에 녹여 헥산에 부어서 석출시키는 재침전을 2 번 반복하 여 $\mathrm{R}_{8} \mathrm{~S}-\mathrm{nVAc}$ 를 얻었다. 얻어진 합성물의 구조는 TOF-MS

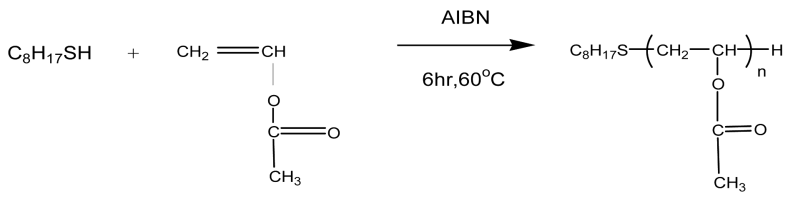

R $\mathrm{R}_{8} \mathrm{~S}-\mathrm{nVAC}$

Scheme 1. Synthesis of $\mathrm{R}_{8} \mathrm{~S}-\mathrm{nVAc}$

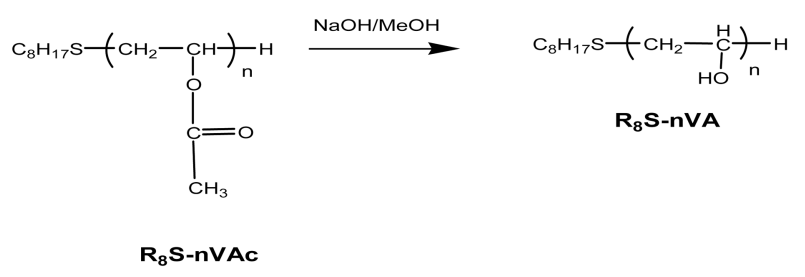

Scheme 2. Hydrolysis of $\mathrm{R}_{8} \mathrm{~S}-\mathrm{nVAc}$

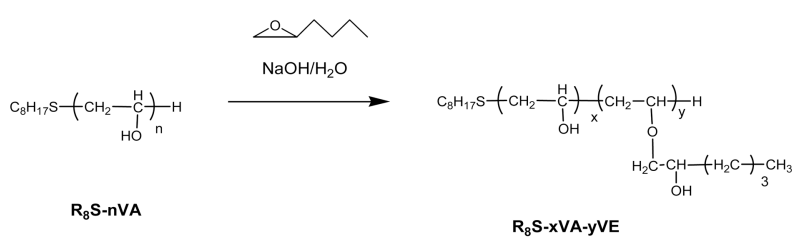

Scheme 3. 1,2-Epoxyhexane introduction to $\mathrm{R}_{8} \mathrm{~S}-\mathrm{nVAa}$

spectrum, ${ }^{1} \mathrm{HNMR}$-spectrum, IR spectrum 및 원소분석 등에 의해 확인하였다.

$\mathrm{R}_{8} \mathrm{~S}-\mathrm{nVAc}$ 의 가수분해: $\mathrm{R}_{8} \mathrm{~S}-\mathrm{nVAc}$ 량에 대하여 5 배 mol 의 Sodium hydroxide/Methanol 용액을 조제하였다. $\mathrm{R}_{8} \mathrm{~S}-\mathrm{nVAc} /$ Methanol 용액에 sodium hydroxide 용액을 가하여 2시간 교반 한 후, 방치하였다가 생성된 백색침전을 메탄올로 세정 후 감 압증류시켜 건조하였다. ${ }^{1} \mathrm{HNMR}$-spectrum, IR spectrum 및 원 소분석으로 목적물을 확인하였다.

$\mathrm{R}_{8} \mathrm{~S}-\mathrm{nVA}$ 를 사용한 1.2-Epoxyhexane의 도입: $\mathrm{R}_{8} \mathrm{~S}-\mathrm{nVA}$ $2.0 \mathrm{~g}$ 과 1.2-Epoxyhexane $3.3 \mathrm{~g}$ 을 $0.4 \mathrm{~mol} / \mathrm{L} \mathrm{NaOH} / \mathrm{H}_{2} \mathrm{O}$ 용액 $50 \mathrm{ml}$ 에 혼합시켜, $25^{\circ} \mathrm{C}$ 에서 2 시간 교반하였다. 그 후 혼합용 액을 $80^{\circ} \mathrm{C}$ 에서 3 시간 교반한 후 혼합용액을 감압 증류하여 헥 산으로 3 회 세정, 건조시켜 목적물을 얻었다. 합성물은 ${ }^{1} \mathrm{HNMR}-$ spectrum, IR spectrum 및 원소분석으로 목적물을 확인하였다.

\section{3. 코텔로머의 특성 평가}

합성한 cotelomer의 화학구조 및 조성분석은 핵자기 공명분 광기(JNM-EX400 FT NMR spectrometer, JEOL)와 적외분광광 도계(IR408, SHIMADZU)를 사용하여 분석하였다. 질량분석은 비행시간성질량분석기(Q-TOF-MS, WATERS MICROMASS)로, 흡광도는 자외가시광선 분광분석기(HITACHIU-3210 spectrometer, HITACHIU)를 사용하여 측정하였으며, 진동항온조는 TAITEC Personal H-10((TAITEC)을 사용하였다. 
표면장력은 각 농도로 조정한 수용액 $10 \mathrm{~cm}^{-3}$ 을 각각 schale에 넣어, 24시간 방치한 후 platinum ring을 사용하는 $\mathrm{Du}$ Noüy tensiometer(Ikemoka Ltd.)를 사용하여 $25^{\circ} \mathrm{C}$ 에서 측정하였고, 계 면장력은 각 농도로 조정한 수용액 $20 \mathrm{~cm}^{-3}$ 과 ethanol $20 \mathrm{~cm}^{-3}$ 을 schale에 넣어, 24시간 방치한 후 platinum ring을 사용하는 $\mathrm{Du}$ Noüy tensiometer(Ikemoka Ltd.)를 사용하여 $25^{\circ} \mathrm{C}$ 에서 측 정하였다.

기포력은 $20 \mathrm{mg}$ 의 sample을 ion 교환수 $10 \mathrm{ml}$ 에 용해시켜, 눈금이 붙은 시험관 중에서 3 시간 방치하여 침지시킨 후 경시 변화에 따른 foam 양을 $25^{\circ} \mathrm{C}$ 에서 측정하였다. 유화능은 $50 \mathrm{ml}$ 눈금이 붙은 시험관에 소정농도의 수용액 $10 \mathrm{~cm}^{-3}$ 와 toluene $10 \mathrm{~cm}^{-3}$ 를 넣고, 30 분간 초음파 조사 후 30 분간 침지하여, 경시 변화에 따른 emulsion 상의 비율을 $25^{\circ} \mathrm{C}$ 에서 추적하였다.

2.4. $x R_{n} M A-y V A$ 를 사용한 sodium tetraborate decahydrate의 가교반응

온도계, 환류냉각관, 질소 도입관, 적하 funnel을 부착한 4 구 플라스크에, Ethanol로 용해시킨 2-Aminoethanthiol hydrochloride, Methacrylic ester $\left(\mathrm{R}_{\mathrm{n}} \mathrm{MA}\right)$ 및 $\mathrm{VAc}$ 를 소정량 넣어, monomer에 대하여 $1.0 \mathrm{wt} \%$ 의 $\mathrm{AIBN}$ 을 가하여, 질소기류 하 $60^{\circ} \mathrm{C}$ 에서 6 시 간 교반하였다. 반응용액은 ethanol을 감압증류 후, Hexane에 부 어서 세정하고, 석출한 점상 물질을 Methanol에 녹여 Hexane에 부어서 석출시키는 재침전을 2 번 반복하여 $1.1 \mathrm{R}_{6} \mathrm{MA}-8.8 \mathrm{VAc}$ 를 얻었다.

이렇게 얻은 $1.1 \mathrm{R}_{6} \mathrm{MA}-8.8 \mathrm{VAc}$ 량에 대하여 5 배 $\mathrm{mol}$ 의 Sodium hydroxide/Methanol 용액을 조정하였다. Cotelomer/ Methanol 용액에 Sodium hydroxide 용액을 가하여 2시간 교 반한 후, 가만히 두었다. 생성한 백색침전을 Methanol로 세정 후 감압증류 하여 가수분해 하여 cotelomer $1.1 \mathrm{R}_{6} \mathrm{MA}-8.8 \mathrm{VA}$ 를 얻었다.

물 $50 \mathrm{ml}$ 에 cotelomer $1.1 \mathrm{R}_{6} \mathrm{MA}-8.8 \mathrm{VA} \quad 2.5 \mathrm{~g}$ 을 용해시켜 $80^{\circ} \mathrm{C}$ 로 승온하였다. 그 후, Sodium tetraborate decahydrate
$0.9 \mathrm{~g}$ 을 물 $50 \mathrm{ml}$ 에 용해시켜 cotelomer 용액을 혼합하고, 그 혼합액을 $80^{\circ} \mathrm{C}$ 에서 2 시간 가열 교반하였다. 그 후 혼합용액을 감압증류하여 Methanol 용액으로 3회 세정, 건조시켜 목적물을 얻었다. 합성물은 ${ }^{1} \mathrm{HNMR}$-spectrumTOF-MS spectrum, IR spectrum으로 목적물을 확인하였다.

\section{3. 결과 및 고찰}

\section{1. $\mathrm{R}_{8} \mathrm{~S}-\mathrm{nVA}$ 를 사용한 1.2-epoxyhexane의 도입}

1-Octanethiol-Vinylacetate telomer $\left(\mathrm{R}_{8} \mathrm{~S}-\mathrm{nVAc}\right)$ 의 합성: 합 성한 1-Octanethiol-Vinylacetate telomer $\left(\mathrm{R}_{8} \mathrm{~S}-\mathrm{nVAc}\right)$ 의 화학구조 및 조성성분은 ${ }^{1} \mathrm{H}-\mathrm{NMR}$ 스펙트럼, FT-IR 스펙트럼을 사용하여 분석하였으며, 분석결과는 Table 1에 합성조건 및 합성결과는 Table 2에 나타내었다.

합성한 $\mathrm{R}_{8} \mathrm{~S}-8.8 \mathrm{VAc}$ 의 ${ }^{1} \mathrm{H}-\mathrm{NMR}$ 스펙트럼 분석을 위한 용매 는 Deutetrated chloroform $\left(\mathrm{CDCl}_{3}\right)$ 를 사용하였다. Table 1에 서 알 수 있듯이 $0.9 \mathrm{ppm}$ 의 크기는 $\mathrm{CH}_{3}$-(a)에 의한 피크이며, $1.1-1.4 \mathrm{ppm}$ 의 크기는 $-\left(\mathrm{CH}_{2}\right)_{3}-(\mathrm{b}), 1.6 \mathrm{ppm}$ 에서 $-\mathrm{CH}_{2}(\mathrm{~b}$ '), $2.1 \mathrm{ppm}$ 에서 $-\mathrm{CH}_{3}(\mathrm{f}), 2.5 \mathrm{ppm}$ 에서 $-\mathrm{CH}_{2} \mathrm{~S}-(\mathrm{c})$, 그리고 $4.2 \mathrm{ppm}$ 에서 $\mathrm{CH}-(\mathrm{e})$ 에 의한 피크가 나타났다.

FT-IR 스펙트럼에서는 $1226 \mathrm{~cm}^{-1}$ 에서 $\mathrm{C}-\mathrm{O}$ 의 신축진동, $1735 \mathrm{~cm}^{-1}$ 에서 $\mathrm{C}=\mathrm{O}$ 의 신축진동, $2926 \mathrm{~cm}^{-1}$ 에서 $\mathrm{C}-\mathrm{H}$ 간의 신축 진동에 의한 피크를 확인하였다.

$\mathrm{R}_{8} \mathrm{~S}-8.8 \mathrm{VAc}$ 의 가수분해: 가수분해 후의 $\mathrm{R}_{8} \mathrm{~S}-8.8 \mathrm{VA}$ 의 화학구 조 및 조성성분은 ${ }^{1} \mathrm{H}-\mathrm{NMR}$ 스펙트럼, FT-IR 스펙트럼을 사용 하여 분석하였다. 분석 결과는Table 1 에, 합성조건 및 합성결과 는 Table 2에 나타내었다.

합성한 $\mathrm{R}_{8} \mathrm{~S}-8.8 \mathrm{VAc}$ 의 ${ }^{1} \mathrm{H}-\mathrm{NMR}$ 스펙트럼 분석을 위한 용매 는 Heavy water $\left(\mathrm{D}_{2} \mathrm{O}\right)$ 를 사용하였다. Table 1 에서 알 수 있 듯이 $0.9 \mathrm{ppm}$ 의 크기는 $\mathrm{CH}_{3}$-(a)에 의한 피크이며, $1.1-1.4 \mathrm{ppm}$ 의 크기는 - $\mathrm{CH}_{2}\left(\mathrm{~b}^{\prime}\right), 1.5-2.0 \mathrm{ppm}$ 에서 - $\left(\mathrm{CH}_{2}\right)_{3}(\mathrm{~b}), 2.7-2.9 \mathrm{ppm}$ 에서 $-\mathrm{CH}_{2}(\mathrm{c})$, 그리고 $3.7-4.1 \mathrm{ppm}$ 에서 $-\mathrm{CH}_{2}-\mathrm{CH}(\mathrm{d}, \mathrm{e})$ 에 의한

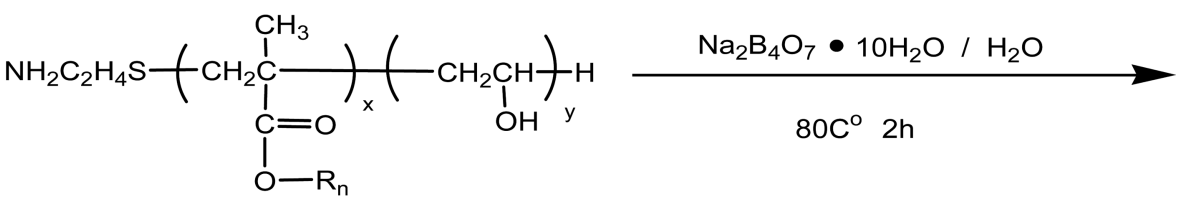

\section{$X R_{n} M A-y V A$}

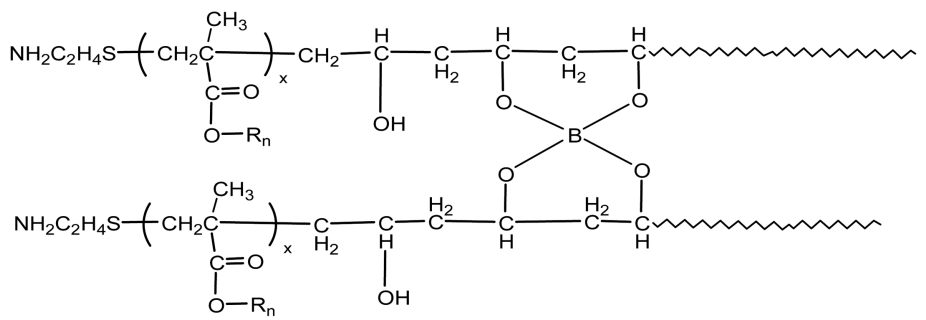

Scheme 4. $\mathrm{xR}_{\mathrm{n}} \mathrm{MA}-8.8 \mathrm{VA}$ crosslinking with Sodium tetraborate decahydrate 
Table 1. ${ }^{1} \mathrm{H}-\mathrm{NMR}$ spectrum and FT-IR spectrum result of $\mathrm{R}_{8} \mathrm{~S}-8.8 \mathrm{VAc}, \mathrm{R}_{8} \mathrm{~S}-8.8 \mathrm{VA}$ and $\mathrm{R}_{8} \mathrm{~S}-0.6 \mathrm{VE}-0.8 \mathrm{VA}$

\begin{tabular}{|c|c|c|c|}
\hline & Telomer $\mathrm{R}_{8} \mathrm{~S}-8.8 \mathrm{VAc}$ & Telomer $\mathrm{R}_{8} \mathrm{~S}-8.8 \mathrm{VA}$ & Cotelomer $\mathrm{R}_{8} \mathrm{~S}-0.6 \mathrm{VE}-8.8 \mathrm{VA}$ \\
\hline $\begin{array}{l}\text { Chemical } \\
\text { structure }\end{array}$ & 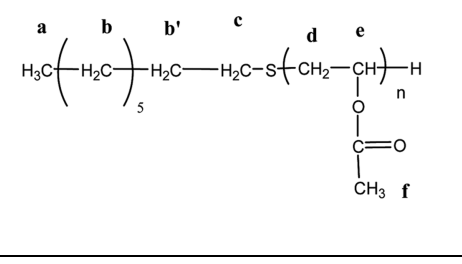 & 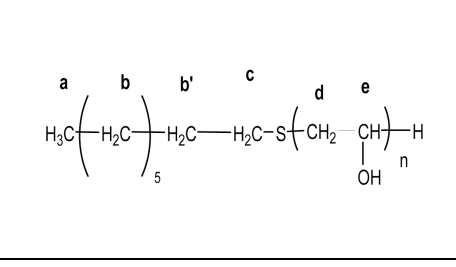 & 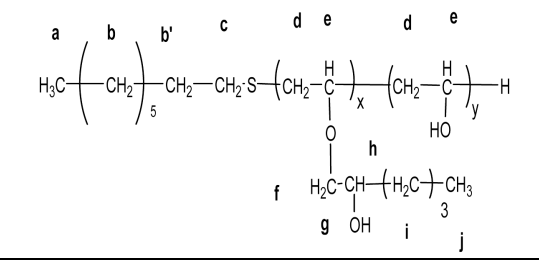 \\
\hline $\begin{array}{l}{ }^{1} \mathrm{H}-\mathrm{NMR} \\
\text { spectrum }\end{array}$ & $\begin{array}{c}\text { Solv. } \mathrm{CDCl}_{3} \\
0.9 \mathrm{ppm}: 3 \mathrm{H}-\mathrm{CH}_{3}(\mathrm{a}) \\
1.2-1.4 \mathrm{ppm}: 6 \mathrm{H}-\left(\mathrm{CH}_{2}\right)_{3}-(\mathrm{b}) \\
1.6 \mathrm{ppm}: 2 \mathrm{H}-\mathrm{CH}_{2}(\mathrm{~b}) \\
2.1 \mathrm{ppm}: 3 \mathrm{H}-\mathrm{CH}_{3}(\mathrm{f}) \\
2.5 \mathrm{ppm}: 2 \mathrm{H}-\mathrm{CH}_{2} \mathrm{~S}-(\mathrm{c}) \\
2.7 \mathrm{ppm}: 1 \mathrm{H}-\mathrm{CH}_{-}(\mathrm{e}) \\
4.2 \mathrm{ppm}: 2 \mathrm{H}-\mathrm{S}_{-}-\mathrm{CH}_{2}-(\mathrm{d})\end{array}$ & $\begin{array}{c}\text { Solv. } \mathrm{D}_{2} \mathrm{O} \\
0.9 \mathrm{ppm}: 3 \mathrm{H}-\mathrm{CH}_{3}(\mathrm{a}) \\
1.1-1.4 \mathrm{ppm}: 2 \mathrm{H}-\mathrm{CH}_{2}(\mathrm{~b}) \\
1.5-2.0 \mathrm{ppm}: 6 \mathrm{H}-\left(\mathrm{CH}_{2}\right)_{3}(\mathrm{~b}) \\
2.7-2.9 \mathrm{ppm}: 2 \mathrm{H}-\mathrm{CH}_{2}(\mathrm{c}) \\
3.7-4.1 \mathrm{ppm}: 3 \mathrm{H}-\mathrm{CH}_{2}-\mathrm{CH}(\mathrm{d}, \mathrm{e})\end{array}$ & $\begin{array}{c}\text { Solv. } \mathrm{D}_{2} \mathrm{O} \\
0.9 \mathrm{ppm}: 3 \mathrm{H}-\mathrm{CH}_{3}(\mathrm{a}, \mathrm{j}) \\
1.2-1.8 \mathrm{ppm}: 6 \mathrm{H}-\left(\mathrm{CH}_{2}\right)_{3}, 2 \mathrm{H}-\mathrm{CH}_{2}(\mathrm{~b}, \mathrm{~b}, \quad, \mathrm{i}) \\
1.9 \mathrm{ppm}: 2 \mathrm{H}-\mathrm{CH}_{2} \mathrm{~S}-(\mathrm{c}) \\
3.3-3.8 \mathrm{ppm}: 3 \mathrm{H}-\mathrm{CH}_{2}-\mathrm{CH}(\mathrm{f}, \mathrm{g}, \mathrm{h}) \\
\text { 3.9-4.1 ppm }: 3 \mathrm{H}-\mathrm{CH}_{2}-\mathrm{CH}(\mathrm{d}, \mathrm{e})\end{array}$ \\
\hline $\begin{array}{c}\text { FT-IR } \\
\text { spectrum }\end{array}$ & $\begin{array}{ll}1226 \mathrm{~cm}^{-1}: & \mathrm{C}-\mathrm{O} \text { stretching vibration } \\
1735 \mathrm{~cm}^{-1}: & \mathrm{C}=\mathrm{O} \text { stretching vibration } \\
2926 \mathrm{~cm}^{-1}: & \mathrm{C}-\mathrm{H} \text { stretching vibration }\end{array}$ & $\begin{array}{ll}1024 \mathrm{~cm}^{-1}: & \text { C-H bending vibration } \\
2941 \mathrm{~cm}^{-1}: & \text { C-H stretching vibration } \\
3309 \mathrm{~cm}^{-1}: & \text { O-H stretching vibration }\end{array}$ & $\begin{array}{l}1088 \mathrm{~cm}^{-1}: \mathrm{C}-\mathrm{O}-\mathrm{C} \text { inverse symmetrical } \\
\text { stretching vibration } \\
1438 \mathrm{~cm}^{-1}: \mathrm{CH}_{2}-\mathrm{S} \text { symmetrical bending } \\
\text { vibration } \\
2940 \mathrm{~cm}^{-1}: \mathrm{C}-\mathrm{H} \text { of methylene function } \\
\text { stretching vibration } \\
3273 \mathrm{~cm}^{-1}: \mathrm{OH} \text { stretching vibration }\end{array}$ \\
\hline
\end{tabular}

피크가 나타났다.

FT-IR 스펙트럼에서는 $1024 \mathrm{~cm}^{-1}$ 에서 C-H 변각진동, $2941 \mathrm{~cm}^{-1}$ 에서 $\mathrm{C}-\mathrm{H}$ 의 신축진동, $3309 \mathrm{~cm}^{-1}$ 에서 $\mathrm{O}-\mathrm{H}$ 간의 신축진동에 의한 피크를 확인하였다.

1.2-Epoxyhexane을 도입한 후의 $\mathrm{R}_{8} \mathrm{~S}-\mathrm{xVE}-\mathrm{yVA}: \mathrm{R}_{8} \mathrm{~S}$ $8.8 \mathrm{VA}$ 를 사용하여 1.2-Epoxyhexane을 도입한 후의 $\mathrm{R}_{8} \mathrm{~S}$ $0.6 \mathrm{VE}-8.8 \mathrm{VA}$ 의 화학구조 및 조성성분은 ${ }^{1} \mathrm{H}-\mathrm{NMR}$ 스펙트럼, FT-IR 스펙트럼을 사용하여 분석하였으며, 분석결과는 Table 1 에 합성조건 및 합성결과는 Table 2에 나타내었다.

1.2-Epoxyhexane 도입 후의 $\mathrm{R}_{8} \mathrm{~S}-0.6 \mathrm{VE}-8.8 \mathrm{VA}$ 의 ${ }^{1} \mathrm{H}-\mathrm{NMR}$ 스펙트럼 분석을 위한 용매는 heavy water $\left(\mathrm{D}_{2} \mathrm{O}\right)$ 를 사용하였 다. Table 1 에서 알 수 있듯이 $0.9 \mathrm{ppm}$ 의 크기는 $\mathrm{CH}_{3}$-(a,j)에 의한 피크이며, $1.2-1.8 \mathrm{ppm}$ 의 크기는 $-\left(\mathrm{CH}_{2}\right)_{3},-\mathrm{CH}_{2}(\mathrm{~b}, \mathrm{~b}, \mathrm{i})$,

Table 2. Synthesis results of $\mathrm{R}_{8} \mathrm{~S}-\mathrm{xVE}-\mathrm{yVA}$

\begin{tabular}{|c|c|c|c|c|}
\hline \multicolumn{5}{|c|}{ Synthesis conditions and the results of $\mathrm{R}_{8} \mathrm{~S}-\mathrm{nVAc}$ telomerization } \\
\hline Composition & $\beta$ & Quantity(g) & Yield $(\%$ & Polymerization $\left(\mathrm{P}_{\mathrm{n}}\right)$ \\
\hline $\mathrm{R}_{8} \mathrm{~S}-8.8 \mathrm{VAc}$ & 0.1 & 15.9 & 41 & 8.8 \\
\hline \multicolumn{5}{|c|}{ Hydrolysis results of $\mathrm{R}_{8} \mathrm{~S}-\mathrm{nVAc}$} \\
\hline Composition & Quantity(g) & Yield(\%) & & HLB \\
\hline $\mathrm{R}_{8} \mathrm{~S}-8.8 \mathrm{VA}$ & 10.4 & 49 & & 16.3 \\
\hline \multicolumn{5}{|c|}{ Synthesis results of $\mathrm{R}_{8} \mathrm{~S}-\mathrm{xVE}-\mathrm{yVA}$} \\
\hline Composition & Quantity(g) & & Yiel & $(\%)$ \\
\hline $\begin{array}{l}\mathrm{R}_{8} \mathrm{~S}-0.6 \mathrm{VE}- \\
8.8 \mathrm{VA}\end{array}$ & 1.66 & & 42 & \\
\hline
\end{tabular}

$\beta=\operatorname{Thiol}(\mathrm{mol}) / \mathrm{VAc}(\mathrm{mol})+\mathrm{R}_{8} \mathrm{~S}(\mathrm{~mol})$
$1.9 \mathrm{ppm}$ 에서 - $\mathrm{CH}_{2} \mathrm{~S}-(\mathrm{c}), 3.3-3.8 \mathrm{ppm}$ 에서 $-\mathrm{CH}_{2}-\mathrm{CH}(\mathrm{f}, \mathrm{g}, \mathrm{h})$, 그리 고 3.9-4.1 ppm에서 - $\mathrm{CH}_{2}-\mathrm{CH}(\mathrm{d}, \mathrm{e})$ 에 의한 피크가 나타났다.

FT-IR 스펙트럼에서는 $1088 \mathrm{~cm}^{-1}$ 에서 C-O-C 역대칭 신축운 동, $1438 \mathrm{~cm}^{-1}$ 에서 $\mathrm{CH}_{2}$-S의 대칭변각진동, $2940 \mathrm{~cm}^{-1}$ 에서 메틸 렌기의 C-H 신축진동, $3273 \mathrm{~cm}^{-1}$ 에서 $\mathrm{O}-\mathrm{H}$ 간의 신축진동에 의 한 피크를 확인하였다.

\subsection{2-Epoxyhexane을 도입한 후의 $\mathrm{R}_{8} \mathrm{~S}-0.6 \mathrm{VE}-8.8 \mathrm{VA}$ 의}

\section{특성}

표면특성: Fig. 1 에 $\mathrm{R}_{8} \mathrm{~S}-\mathrm{xVA}$ 와 $\mathrm{R}_{8} \mathrm{~S}-0.6 \mathrm{VE}-8.8 \mathrm{VA}$ 의 표면장 력 측정결과를 보인다. 표면장력은 cotelomer의 농도가 증가함 에 따라 감소하였고, break point에 이르렀을 때 그 값을 임계 미셀농도 $(\mathrm{cmc})$ 로 취했다. $\mathrm{R}_{8} \mathrm{~S}-8.8 \mathrm{VA}$ 의 표면장력 $\gamma_{\mathrm{cmc}}$ 는 $38.1 \mathrm{~m} \mathrm{Nm}^{-1}$, 1.2-Epoxyhexane 도입 후에는 $39.2 \mathrm{mNm}^{-1}$ 로 1.2-Epoxyhexane 도입 후의 $\gamma_{\mathrm{cmc}}$ 가 약 $1.1 \mathrm{mNm}^{-1}$ 증가는 하였 으나 큰 변화를 보이지 않았다. 그러나 $\mathrm{cmc}$ 는 양쪽 다 $2.2 \times 10^{-3} \mathrm{~mol} \cdot \mathrm{L}^{-1}$ 로 변화를 보이지 않았다. 일반적으로 친수기가 증가하면 $\mathrm{cmc}$ 와 표면장력은 증가하게 되는데, 1.2-Epoxyhexane 의 도입에 의해 친수기의 에폭시기 도입량이 적어 $\mathrm{cmc}$ 의 증가 는 약간 있었으나 $\mathrm{cmc}$ 에는 변화가 없었다고 볼 수 있다.

계면장력: Fig. 2에 $\mathrm{R}_{8} \mathrm{~S}-8.8 \mathrm{VA}$ 와 1.2-Epoxyhexane 도입 후 의 $\mathrm{R}_{8} \mathrm{~S}-0.6 \mathrm{VE}-8.8 \mathrm{VA}$ 의 계면장력 측정결과를 보였다. 계면장력 은 모두 $0 \mathrm{mNm}^{-1}$ 을 보였고, $\mathrm{cmc}$ 는 $1.3 \times 10^{-3} \mathrm{~mol} \cdot \mathrm{L}^{-1}$ 로 변화를 보이지 않았다.

유화능 측정: Fig. 3에 $\mathrm{R}_{8} \mathrm{~S}-8.8 \mathrm{VA}$ 와 1.2-Epoxyhexane 도입 후의 $\mathrm{R}_{8} \mathrm{~S}-0.6 \mathrm{VE}-8.8 \mathrm{VA}$ 의 유화능 측정결과를 보였다. $\mathrm{R}_{8} \mathrm{~S}-$ 


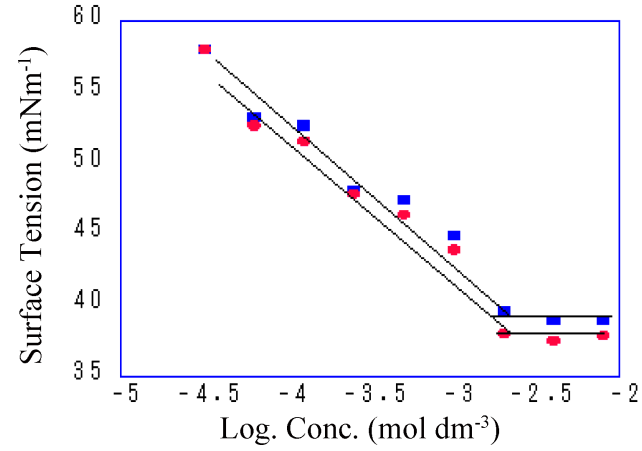

Fig. 1. Relationship between logarithm of concentration and surface tension of $\mathrm{R}_{8} \mathrm{~S}-8.8 \mathrm{VA}$ and after 1,2-Epoxyhexane introduction at $25^{\circ} \mathrm{C}$. ०: $\mathrm{R}_{8} \mathrm{~S}-8.8 \mathrm{VA}$

$$
\text { 口: } \mathrm{R}_{8} \mathrm{~S}-0.6 \mathrm{VE}-8.8 \mathrm{VA} \text {. }
$$

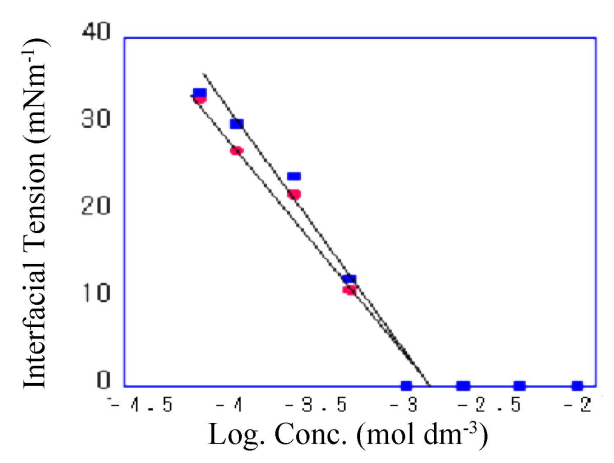

Fig. 2. Relationship between logarithm of concentration and interfacial tension of $\mathrm{R}_{8} \mathrm{~S}-8.8 \mathrm{VA}$ and after 1,2-Epoxyhexane introduction at $25^{\circ} \mathrm{C}$. - $\mathrm{R}_{8} \mathrm{~S}-8.8 \mathrm{VA}, \mathbf{\square}: \mathrm{R}_{8} \mathrm{~S}-0.6 \mathrm{VE}-8.8 \mathrm{VA}$.

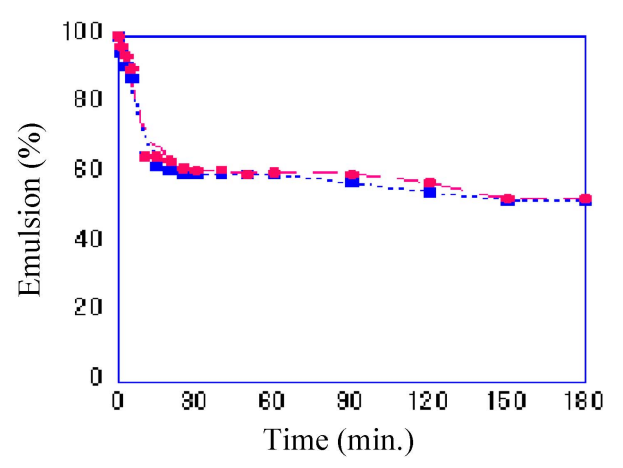

Fig. 3. Degree of emulsification of $\mathrm{R}_{8} \mathrm{~S}-8.8 \mathrm{VA}$ and after 1,2Epoxyhexane introduction.

- $\mathrm{R}_{8} \mathrm{~S}-8.8 \mathrm{VA}, \mathbf{\mathbf { a }}: \mathrm{R}_{8} \mathrm{~S}-0.6 \mathrm{VE}-8.8 \mathrm{VA}$.

8.8VA, $\mathrm{R}_{8} \mathrm{~S}-0.6 \mathrm{VE}-8.8 \mathrm{VA}$ 모두 $\mathrm{O} / \mathrm{W}$ emulsion을 형성하였고, 유화능은 $\mathrm{R}_{8} \mathrm{~S}-8.8 \mathrm{VA}$ 가 $53 \%, \mathrm{R}_{8} \mathrm{~S}-0.6 \mathrm{VE}-8.8 \mathrm{VA}$ 가 $52.5 \%$ 로 1.2-Epoxyhexane 도입 후 약 $0.5 \%$ 정도 감소하였으나 역시 그 차이는 미미하였다.

기포력 측정: Fig. 4에 $\mathrm{R}_{8} \mathrm{~S}-\mathrm{xVA}$ 와 1.2-Epoxyhexane 도입

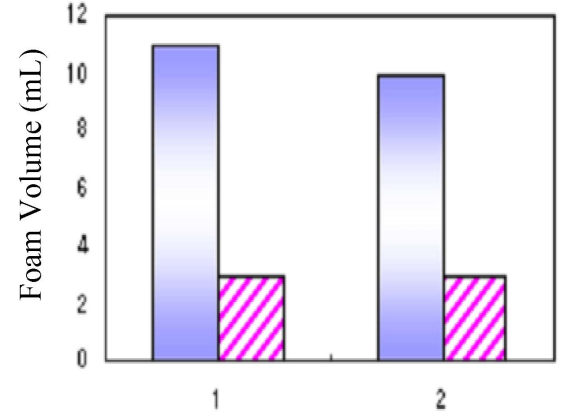

Fig. 4. Foaming abilities of $\mathrm{R}_{8} \mathrm{~S}-8.8 \mathrm{VA}$ and after 1,2-Epoxyhexane introduction. $\square$ : Foam ability, $\square$ : Foam stability, 1. $\mathrm{R}_{8} \mathrm{~S}-8.8 \mathrm{VA}, 2$. $\mathrm{R}_{8} \mathrm{~S}-0.6 \mathrm{VE}-8.8 \mathrm{VA}$.

후의 $\mathrm{R}_{8} \mathrm{~S}-0.6 \mathrm{VE}-8.8 \mathrm{VA}$ 의 기포력 측정결과를 보였다. 기포력은 $\mathrm{R}_{8} \mathrm{~S}-8.8 \mathrm{VA}$ 가 $11 \mathrm{ml}, \mathrm{R}_{8} \mathrm{~S}-0.6 \mathrm{VE}-8.8 \mathrm{VA}$ 는 $10 \mathrm{ml}$ 로 그 차이는 아주 작았으며, 거품 안정성은 양쪽 모두 $3 \mathrm{ml}$ 로 같은 값을 보 여, 표면장력의 변화도 아주 작다고 볼 수 있다. 계면활성제 수 용액의 거품 안정성은 표면장력 값과 밀접한 관계가 있다. 계 면활성제의 표면장력이 큰 경우에는 공기와 수용액의 계면에 흡착하는 계면활성제의 표면에너지 저하 효과가 낮으므로 계면 은 상대적으로 높은 에너지 상태를 유지하게 되어 거품이 불안 정하여 쉽게 깨지게 된다(Lim et al., 2011).

Cotelomer $\mathrm{R}_{8} \mathrm{~S}-\mathrm{xVA}$ 에 1.2-Epoxyhexane을 도입하는 실험을 행하였는데, 이상의 결과로부터 계면활성에 큰 변화를 보이지 않고 epoxy기를 도입할 수 있음을 알 수 있었다.

3.3. $x R_{n} M A-y V A$ 를 사용한 Sodium tetraborate decahydrate 의 가교 후 특성

$1.1 \mathrm{R}_{6} \mathrm{MA}-8.8 \mathrm{VA}$ cotelomer $2.5 \mathrm{~g}$ 과 Sodium tetraborate decahydrate $0.9 \mathrm{~g}$ 의 가교반응으로부터 얻은 $1.2 \mathrm{~g}$ 가교물의 FTIR 스펙트럼에서는 $3211 \mathrm{~cm}^{-1}$ 에서 $\mathrm{O}-\mathrm{H}$ 신축진동, $2935 \mathrm{~cm}^{-1}$ 에 서 $\mathrm{C}-\mathrm{H}$ 의 신축진동, $1416 \mathrm{~cm}^{-1}$ 에서 $\mathrm{CH}_{2}-\mathrm{NH}_{2}$ 의 C-N 신축진동, $1333 \mathrm{~cm}^{-1}$ 에서 B-O 신축진동에 의한 피크를 확인하여 B-O 결 합을 확인하였다.

표면장력: Fig. 5 에 $1.1 \mathrm{R}_{6} \mathrm{MA}-8.8 \mathrm{VA}$ 와 가교 후의 표면장력 측정결과를 나타내었다. $1.1 \mathrm{R}_{6} \mathrm{MA}-8.8 \mathrm{VA}$ 의 표면장력 $\gamma_{\mathrm{cmc}}$ 는 $39 \mathrm{mNm}^{-1}$, 가교 후에는 $42 \mathrm{mNm}^{-1}$ 로 가교 후 표면장력의 증가 는 $3 \mathrm{mNm}^{-1}$ 이었다. 가교 전의 $1.1 \mathrm{R}_{6} \mathrm{MA}-8.8 \mathrm{VA}$ 가 더 양호한 표면장력 저하능을 보였다. 또 임계미셀농도 $\mathrm{cmc}$ 는 양쪽 모두 $3 \mathrm{gL}^{-1}$ 로 같은 값을 보였다. $\mathrm{cmc}$ 와 표면장력은 친수성이 증가 하면 증가하기 때문에 Sodium tetraborate decahydrate의 가교 작용에 의해 형성된 친수기의 B-O 결합 때문에 $\gamma_{\mathrm{cmc}}$ 가 약간 증가하였으나, $\mathrm{cmc}$ 에는 변화가 없었다고 볼 수 있다.

계면장력: Fig. 6에 $1.1 \mathrm{R}_{6} \mathrm{MA}-8.8 \mathrm{VA}$ 와 가교 후의 계면장력 측정결과를 보였다. 계면장력과 임계미셀농도 $\mathrm{cmc}$ 는 가교 전 이나 후 모두 각각 $0 \mathrm{mNm}^{-1}, 3 \mathrm{gL}^{-1}$ 로 되어 계면특성은 전혀 


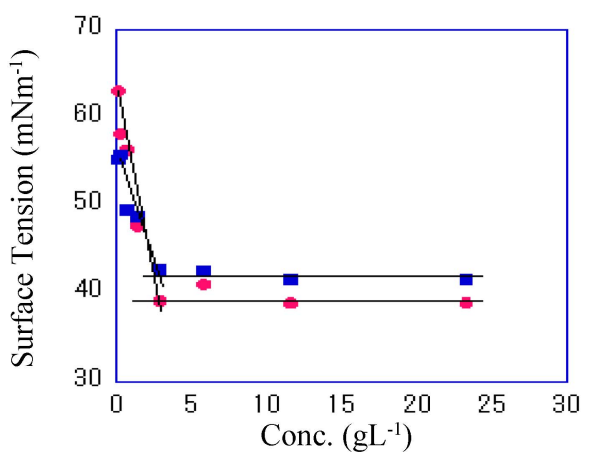

Fig. 5. Relationship between concentration and surface tension of $1.1 \mathrm{R}_{6} \mathrm{MA}-8.8 \mathrm{VA}$ and after cross-linking at $25^{\circ} \mathrm{C}$. $1.1 \mathrm{R}_{6} \mathrm{MA}-8.8 \mathrm{VA}$, 口: After cross-linking.

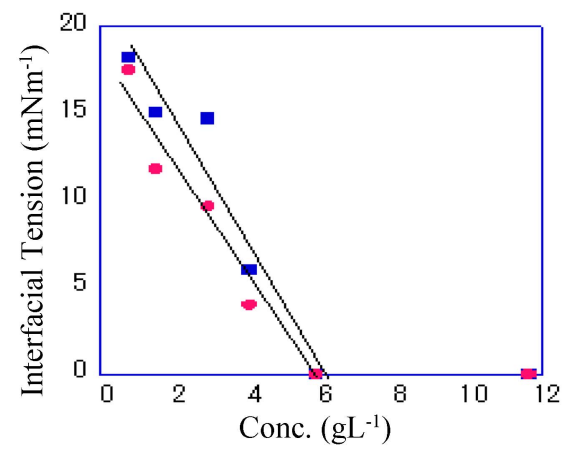

Fig. 6. Relationship between concentration and interfacial tension of 1.1 $\mathrm{R}_{6} \mathrm{MA}-8.8 \mathrm{VA}$ and after cross-linking at $25^{\circ} \mathrm{C} . \mathbf{0} 1.1 \mathrm{R}_{6} \mathrm{MA}-8.8 \mathrm{VA}$, : After cross-linking.

변화가 없었다.

유화능 측정: Fig. 7 에 $1.1 \mathrm{R}_{6} \mathrm{MA}-8.8 \mathrm{VA}$ 와 가교 후의 유화능 측정 결과를 보였다. $1.1 \mathrm{R}_{6} \mathrm{MA}-8.8 \mathrm{VA}$, 가교 후 모두 $\mathrm{O} / \mathrm{W}$ emulsion을 형성하였다. 또 유화능은 가교 전의 $1.1 \mathrm{R}_{6} \mathrm{MA}-$ $8.8 \mathrm{VA}$ 가 $53 \%$, 가교 후 $50 \%$ 로 약 $3 \%$ 의 감소를 보였다.

기포력 측정: Fig. 8 에 $1.1 \mathrm{R}_{6} \mathrm{MA}-8.8 \mathrm{VA}$ 와 가교 후의 기포력 측정결과를 보였다. 기포력은 가교 전의 $1.1 \mathrm{R}_{6} \mathrm{MA}-8.8 \mathrm{VA}$ 가 $9 \mathrm{ml}$, 가교 후 $6 \mathrm{ml}$ 로 기포력은 가교 후에 약 $3 \mathrm{ml}$ 의 감소를 보였다. 그러나 거품 안정성은 양쪽 모두 $1 \mathrm{ml}$ 로 같은 값을 보 여 표면장력의 변화가 거의 없다고 볼 수 있다.

이상의 결과로부터 Sodium tetraborate decahydrate의 가교반 응을 행하였는데, 계면특성에 그다지 변화가 보이지 않았다. Boron은 3족 원소여서 3개의 전자만 얻으면 안정하게 되나 Scheme 4에 보였듯이 Boron은 4개의 산소와 가교를 이루므로 음이온을 띄게 되며, 불안정한 결합을 하게 되므로 B-O 결합 력은 약하게 된다. 따라서 이와 같은 약한 B-O 결합 때문에 계면특성에 큰 영향을 주지 않았다고 생각된다.

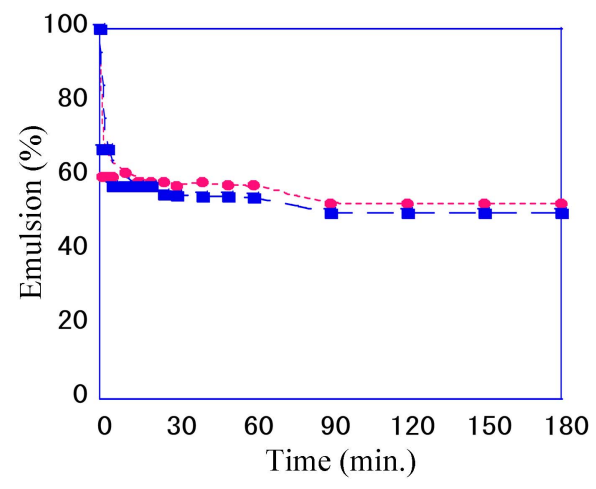

Fig. 7. Degree of emulsification of $1.1 \mathrm{R}_{6} \mathrm{MA}-8.8 \mathrm{VA}$ and after crosslinking. : $1.1 \mathrm{R}_{6} \mathrm{MA}-8.8 \mathrm{VA}, \mathbf{\square}$ : After crosslinking.

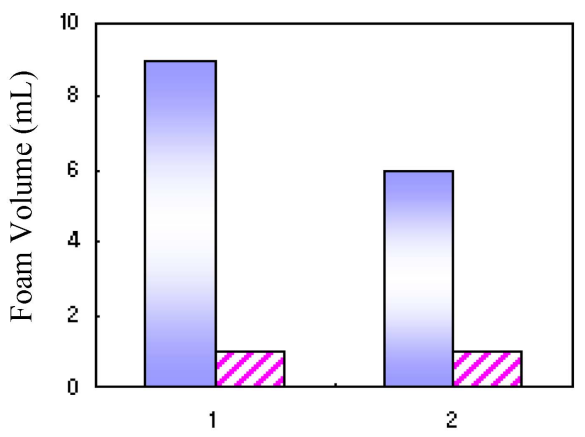

Fig. 8. Foaming abilities of 1.1R6MA-8.8VA and after cross-linking. Foam ability, Foam stability, 1. 1.1R6MA-8.8VA, 2. After cross-linking.

\section{4. 결 론}

본 연구에서는 비이온계 다쇄형 계면활성제 $\mathrm{R}_{8} \mathrm{~S}-\mathrm{nVA}$, $\mathrm{xR}_{6} \mathrm{MA}-\mathrm{yVA}$ 를 사용하여 그 Vinyl alcohol 부분에 1.2Epoxyhexane, Sodium tetraborate decahydrate를 도입하여 계 면화학특성을 검토하는 것을 목적으로 하였다.

1) $\mathrm{R}_{8} \mathrm{~S}-\mathrm{nVA}$ 를 사용한 1.2-Epoxy hexane의 도입실험으로부 터 1.2-Epoxy hexane도입 전의 $\mathrm{R}_{8} \mathrm{~S}-8.8 \mathrm{VA}$ 의 표면장력 $\gamma_{\mathrm{cmc}}$ 가 작고, 표면장력 저하능은 우수하였다. 또 유화능과 기포 안정성 은 $\mathrm{R}_{8} \mathrm{~S}-8.8 \mathrm{VA}$ 가 약간 높았다. 그러나 전반적으로 1.2-Epoxy hexane 도입 전과 후의 계면특성의 변화는 크지 않았다. 이는 epoxy 기의 도입이 적어 계면특성이 크게 변화하지 않은 것으 로 사료된다. 이는 1.2-Epoxy hexane이 $\mathrm{R}_{8} \mathrm{~S}-\mathrm{nVA}$ 의 vinyl alcohol 외에도 용매인 물과도 반응하였기 때문이라고 생각된 다. 그러나 epoxy 기의 도입을 ${ }^{1} \mathrm{H}$ NMR, IR로 확인할 수 있 었기 때문에 계면특성에 큰 영향을 끼치지 않으면서 epoxy 기 를 필요에 따라 도입할 수 있음을 알 수 있었다.

2) $x_{6} \mathrm{MA}-y V A$ 를 사용한 Sodium tetraborate decahydrate의 가교반응실험으로부터 가교전의 $1.1 \mathrm{R}_{6} \mathrm{MA}-8.8 \mathrm{VA}$ 의 표면장력 
$\gamma_{\mathrm{cmc}}$ 가 작고, 표면장력 저하능은 우수하였다. 또 유화능과 기포 안정성은 가교반응 이전이 약간 높았다. 그러나 전반적으로 가 교 전과 후의 계면특성의 변화가 크지는 않았다. 이것은 B-O 결합이 약하였기 때문에 계면특성 등에 큰 영향을 주지 않았다 고 생각된다. 그러나 B-O 결합을 ${ }^{1} \mathrm{H}$ NMR, IR로 확인할 수 있었기 때문에 계면특성에 큰 영향을 끼치지 않으면서 가교반 응을 진행시킬 수 있었다.

\section{감사의 글}

논문은 부산대학교 자유과제 학술연구비(2년)에 의하여 연구 되었음.

\section{References}

Hyun, K., Kim, S. H., Ahn, K. H., \& Lee, S. J. (2002). Large amplitude oscillatory shear as a way to classify the complex fluids. Journal of Non-Newtonian Fluid Mechanics, 107(1-3), 51-65.

Lee, J. H., Choi, H. W., Jung, Y. J., Hwang, D. Y., Choi, Y. H., \& Lee, E. P. (2010). Application of cotelomer type surfactants in the disperse dying. Journal of Textile Science Engineering, 47(1), 4147.

Lim, J. C., Lee, S., Kim, B. J., Lee, J. G., \& Choi K. Y. (2011) Synthesis and characterization of interfacial properties of glycerol surfactant. Applied Chemistry for Engineering. 22(4), 376-383.

Moon C. K., \& Takaku, A. (2006). 고분자 복합재료 [Polymer Matrix Composites]. Seoul: Sigma Press, pp. 116-124.

Shim, J. S., \& Hong S. J. (1962). Studies on telomerization(I) telomerization of vinyl acetate with chlorinated hydrocarbons. Journal of the Korean Chemical Society, 6, 88-93.

Yamada, K. \& Koide, Y. (1981). Telomer type surfactants. Journal of Oleo Science, 30(1), 2-9.

Yoshimura, T., Koid, Y., K., Shosenji, H., \& Esumi, K. (2000). Preparation of cotelomers of acrylic acid and n-hexyl, 2-fthylhexyl or n-dodecyl acrylate and their properties as multi-alkylated surfactants. Journal of Oleo Science, 49(8), 801-808.

Yoshimura, T., Hontake, K., Shosenji, H., \& Esumi, K. (2001a). Preparation and surface activities of cotelomers of acrylic acid and n-octyl, 2-ethylhexyl or 2-phenylethyl acrylate. Journal of Oleo Science, 50(2), 103-108.

Yoshimura, T., Koid, Y., K., Shosenji, H., \& Esumi, K. (2001b). Preparation and surface active properties of cotelomer type surfactants of alkyl acrylate and acrylic acid. Studies in Surface and Catalyses, 132, 145-148.

Yoshimura, T., Kawashima, K., Koid, Y., K., Shosenji, H., \& Esumi, K. (2002a). Surface activities of mixtures of partially-quaternized 2-vinylpyridine telomers and cationic gemini surfactant. Journal of Oleo Science, 51(4), 221-227.

Yoshimura, T., Koid, Y., K., Shosenji, H., \& Esumi, K. (2002b). Preparation and surface active properties of telomer-type anionic surfactants from maleic anhydride. Journal of Surfactants and Detergents, 5(3), 257-262.

Yoshimura, T., Koid, Y., K., Shosenji, H., \& Esumi, K. (2002c). Preparation and surface active properties of n-alkyl maleamic acid telomer type surfactants having several hydrocarbon chains. Journal of Oleo Science, 51(4), 229-236.

(2012년 7월 5일 접수/2012년 7월 23일 1차 수정/ 2012년 7월 25일 2차 수정/2012년 7월 26일 게재확정)

Copyright $(C$ Korean Society for Clothing Industry. 2012. This is an open access article distributed under the terms and conditions of the Creative Commons Attribution Non-Commercial license (http://creativecommons.org/licenses/by-nc/3.0/), which permits unrestricted non-commercial use, distribution, and reproduction in any medium, provided the original work is properly cited. 